\title{
La política en conflicto: la transición o la consolidación ${ }^{1}$
}

\author{
William Ortíz Jiménez² \\ Universidad Nacional, sede Medellín
}

Recibido: 10 de marzo de 2010 • Aprobado: 14 de abril de 2010

\section{esumen}

El siguiente ensayo consiste básicamente en exponer las tesis que han dado origen a las transiciones políticas o el paso de la dictadura hacia la democracia. La cuestión que se plantea es, en términos generales, cómo y por qué un sistema dictatorial evoluciona hacia un sistema democrático. ¿Son necesarias determinadas condiciones culturales, sociales, económicas y políticas para que se produzca la evolución hacia la democracia? O dicho de otro modo: ¿es posible identificar unas formas específicas que nos permitan pronosticar la posibilidad de de una transición hacia la democracia? En este mismo orden de ideas, habrá que considerar que las transiciones sólo son posibles cuando se han dado unos pasos definitivos: la liberalización, la democratización y la consolidación; pasos, por supuesto, vitales para entender el corolario de las transiciones políticas.

Palabras clave: transición, consolidación, democratización, liberalización, dictadura, democracia, reflexión.

1 El presente artículo de reflexión hace parte de la investigación: "Los Paraestados en Colombia”, culminada en 2008.

2 'Doctor en Sociología y Ciencias políticas, Universidad de Granada, España. Magíster en Ciencias Sociales: Cultura y Vida Urbana, Universidad de Antioquia. Profesor asociado de la Universidad Nacional, sede Medellín, departamento de Ciencia Política. 


\section{Policy in conflict: the transition or consolidation}

\section{Albstract}

The following essay is, basically, expose theories which have given source to political transitions or the passage of the dictatorship to democracy. The question is, in general terms, how and why a system dictatorial evolves towards a democratic system...Are they necessary certain cultural, social, economic and political conditions in order that the evolution to produce the evolution towards democracy? In other words, is it possible to identify specific forms that allow us to predict the possibility of a transition to democracy? In this same vein, we must consider that transitions are possible only when there have been some definite steps: liberalization, democratization and consolidation, steps, of course vital to understand the corollary of political transitions.

This is the framework that moves in this essay: show the positions and analysis presented by experts in the field and try to elucidate the characteristics of a possible consolidation, in terms of political scientists, will be the end of the democratization.

Words key: transition, consolidation, democratization, liberalization, dictatorship, democracy. 


\section{La politique en conflit: transition ou consolidation}

\section{ésumé}

Le suivant essai consiste, essentiellement, à exposer les thèses qui ont donné origine aux transitions politiques ou au passage de la dictature à la démocratie. La question qui se pose est, en termes généraux, comment et pourquoi un système dictatorial évolue en direction d'un système démocratique... Est-ce que des conditions culturelles, sociales, économiques et politiques déterminées sont nécessaires pour que se produise l'évolution vers la démocratie? Ou, autrement dit, est-il possible d'identifier des formes spécifiques qui nous permettent de pronostiquer la posiblilité d'une transition vers la démocratie? Dans le même ordre d'idées, il faudra considérer que les transitions sont seulement possibles quand certains pas définitifs ont été faits: la libéralisation, la démocratisation et la consolidation, étapes bien entendu vitales pour comprendre le corrolaire des transitions politiques.

Voici le cadre de référence dans lequel se développe cet essai: montrer les postures et analyses que présentent les experts du thème et tenter d'élucider les caractétistiques propres d'une possible consolidation qui, en termes politologiques, sera le point final de la démocratisation.

Mots - clé: Transition, consolidation, démocratisation, libéralisation, dictature, démocratie, réflexion. 


\section{Introducción}

La manera como se percibe, analiza o define la transición de un sistema político a uno nuevo, o al menos diferente, tiene variadas interpretaciones. Aún así, existe una especie de consenso frente al tema y algunos autores se atreven a considerarla como "el paso de un régimen a otro", o lo que es lo mismo: "de un sistema político a otro". Para los múltiples analistas del tema, no se trata sólo del "paso", sino de la consolidación una vez éste se ha dado.

Me detendré un momento en lo que se puede considerar, entonces, como la transición democrática. En verdad ha sido definida de múltiples formas y es mucha la literatura que existe al respecto, por lo cual es difícil generar un lenguaje común que permita establecer una diferencia más o menos clara de acuerdo con los vocablos utilizados. Lo anterior posibilita la creación de un cierto marco teórico, para lo cual lo intentaré a partir de las lecturas y propuestas elaboradas por autores como Guillermo O'Donnell, Philippe Schmitter, Adam Przeworski y Manuel Antonio Garretón, quienes, a partir de reflexiones fundadas en estudios e indagaciones como las relacionadas en el presente trabajo, muestran análisis asociados a las transiciones, tales como: la asociación, la liberalización, la democratización y la socialización. En cambio, otros autores como Robert Dahl, Giovanni Sartori, Samuel Huntington y Joseph Schumpeter hacen sus enfoques hacia el concepto de democracia.

Una vez definido el anterior marco teórico, es pertinente iniciar con una primera aproximación a lo que puede ser considerado como transición: "intervalo que se extiende entre un régimen político y otro", según la definición dada por O’Donnell, Schmitter y Whitehead (1998). Más adelante agregan:

las transiciones están delimitadas, de un lado, por el inicio de disolución del régimen autoritario, y del otro, por el establecimiento de alguna forma de democracia, el retorno a algún tipo de régimen autoritario o el surgimiento de una alternativa revolucionaria (p.26).

Lo anterior permite observar, según los autores, varias cosas en concreto. La primera es que, por una parte, mediante un proceso de sustitución de un régimen por otro, se desmantela el anterior y se instala uno nuevo y, por otra 
parte, a través de un proceso de desarrollo, el nuevo régimen se diferencia de su predecesor y cristaliza en otra estructura institucional.

Cuando se afirma que se llega a otra estructura institucional, puede que esté implícita la democracia o quizá se caiga en el error de implantar una dictadura, tal y como lo analizaré con los postulados de Przeworski. Pero lo que pretende la transición es llegar a la consolidación de un nuevo sistema que permita el desarrollo de ciertas políticas y alternativas diferentes al gobierno anterior; esto es, indicar que:

Cualquiera sea la forma o tipo de transición, ésta se inicia con la crisis del régimen preexistente y finaliza con la instauración del nuevo. Es decir, la transición termina cuando las instituciones fundamentales del nuevo orden empiezan a organizarse funcionando y relacionándose entre sí de acuerdo con las nuevas reglas de juego (González y Sánchez-Roca, 2000, pp. 154-155).

Lo que demuestra una vez más que sólo es posible analizar la transición cuando un Estado entra en crisis y su forma de Gobierno no responde en cierta manera a las intenciones de sus ciudadanos. Aunque también es de considerar que el nuevo régimen impuesto es el que calcula, estudia y postula las nuevas reglas de juego, que de ninguna manera pueden ser prenda de garantía para considerar que deben ser mejores que las anteriores.

Sin tratar de ser demasiado recurrentes y, en consonancia, con la propuesta de González y Sánchez-Roca (2000), hay que tener en cuenta que depende de la amplitud o intensidad de la crisis y, por tanto, de la relación entre las coaliciones que sostienen al régimen y las coaliciones alternativas existentes, para que la transición tenga lugar a través de la autotransformación del régimen, a través de una serie de pactos entre los diferentes actores políticos o por medio de una ruptura originada por la fuerza creciente de los grupos de la oposición.

En palabras más sencillas: la intensidad o grado de agotamiento de los recursos ideológicos, institucionales, represivos (aún de parte del Estado), personales, económicos y políticos o culturales determina la dimensión de la crisis, y a su vez, caracteriza y condiciona la forma específica de la transición. 
Así podría hacer referencia a una transición pacífica, democrática y consolidada o, simplemente, a una transición violenta, dictatorial y sin consolidación hacia una democracia, situación a la que se pretende llegar una vez aflore la crisis en su totalidad.

Pero, sin lugar a dudas, "no hay evidencia histórica de que una transición pacífica y negociada, contribuya mejor a la consolidación que otras formas de transición política" (González y Sánchez-Roca, 2000, p. 153), aunque así puedan haber postulados contrarios por parte de politólogos y analistas del tema. Posteriormente se tratará de especificar algunos casos de América Latina y Colombia en particular, para observar hasta qué punto tal afirmación posee los suficientes criterios históricos y políticos.

Ahora bien, una vez dada la transición, viene la llamada etapa de consolidación. Claro está que para esta última se necesitan una serie de procesos, como bien pueden ser la institucionalización jurídico-formal del nuevo régimen, pues ningún régimen ha de operar con la misma forma de gobierno, ni con las mismas leyes preexistentes, sino que requiere de la creación y postulación de otras nuevas que permitan la etapa de consolidación, que no es más que el proceso que eventualmente conduce a su institucionalización político-material (empleando el sentido que le da Huntington al término). En un ámbito más amplio, la consolidación abarca todos los procesos por los que el nuevo régimen elimina, reduce a su mínimo o reabsorbe sus iniciales inconsistencias ideológicas e institucionales; afirma su autonomía frente a los poderes de hecho y, en especial, a las fuerzas armadas. Asimismo, moviliza políticamente a la sociedad civil, desarrolla y mantiene un sistema de partidos relativamente estable y capaz de garantizar la estabilidad y conlleva, por supuesto, a un nuevo tipo de gobierno que se consuma con la constitución política y la institucionalización de nuevas leyes pactadas (González y Sánchez-Roca, 2000, p. 54). 
Términos como ruptura pactada ${ }^{3}$ reforma pactada ${ }^{4}$ son expresiones que empiezan a aparecer de manera ambigua, según lo da a conocer Schmitter (1984, pp. 37-44). La primera significa la ausencia de continuidad política entre dos tipos de régimen y los principios de legitimación en los que se apoyan, mientras que la segunda hace referencia y enfatiza en que el proceso formal se inicia derivando de la legalidad anterior. Según Schmitter, ambas fórmulas coinciden en subrayar la importancia del acuerdo, el consenso o el compromiso durante el momento político de sustitución de un régimen por otro.

\section{Las diferentes interpretaciones en torno a la transición}

Aunque es bastante complejo elaborar una síntesis de los postulados de los diversos autores, es preciso observar que las diferentes interpretaciones que han asumido frente al tema no se podrían postular en un orden o con un criterio que demuestre la importancia de uno u otro, sino que en su lugar se asumen una serie de reflexiones libres, sin presiones, de manera que permitan dilucidar el trasfondo de las ideas de cada uno de ellos. En este sentido, parto con los análisis y las investigaciones propuestos por Manuel Antonio Garretón, uno de los teóricos más inquietos frente al tema y a este tipo de posturas teóricas en América Latina, que sirvieron de soporte para otros críticos a nivel internacional.

La crisis de los autoritarismos, la derrota de los regímenes militares y los procesos de transición y consolidación de la democracia política se dan en medio de una crisis que consiste en el agotamiento de un modelo de acumulación

3 El concepto de ruptura se refiere a que los protagonistas de la instauración son las élites, en gran parte nuevas, para las que se crea inmediatamente un interés en el mantenimiento del nuevo régimen democrático. La derrota definitiva de la opción autoritaria puede impulsar a los mismos grupos sociales que inicialmente habían apoyado la opción autoritaria o totalitaria de buscar y encontrar expresión política en el contexto democrático, aceptando las nuevas reglas del compromiso democrático.

4 La reforma significa que si las mismas elites pueden permanecer en el poder, sea cual sea el ordenamiento político, entonces ese orden en sí, se convierte en algo relativamente poco importante. Su adhesión a las regla puede tener un carácter de provisionalidad. La solución Reforma es aceptable si el régimen autoritario ha dejado tales recuerdos negativos que resulte ya impracticable en varios años por las características de su duración, se ha agotado y como ordenamiento político posible cuando la sociedad civil que lo sufre y los actores sociales que estuvieron en su base, se han transformado completamente. 
e inserción internacional y de su intento de reemplazarlo en el contexto de una revolución tecnológica y financiera que parece penetrar y subordinar a todos los países modelos de organización societal desarticulando el mundo de postguerra (Garretón, 1990, p. 2).

Lo anterior no tiene en cuenta las ideologías propias y alternativas posibles en cuanto a las formas de organización política y regímenes de organización alternos a los propuestos por los países vencedores después de la segunda confrontación mundial. Es más, la dependencia política de los países subdesarrollados se traduce en las dictaduras asumidas para controlar los posibles focos de transición política o cambio de régimen; por tal motivo, al agotarse el modelo de dependencia militar y dictatorial o autoritarismo surgido en Europa a través del fascismo y el nazismo, se trasluce a muchos otros del globo casi de manera similar a la impuesta en Europa, pero les hace perder la brújula ante los inminentes cambios que se avecinan en el mundo posmoderno, signado por los avances tecnológicos y las nuevas formas de administración política, militar y el desarrollo económico y científico. De esta manera, la organización societal, según lo expresa Garretón (1990), se desarticula y se inicia un proceso de transición política que se manifiesta en la democracia.

Sin embargo, el concepto de transición democrática ha sido usado para disfrazar diversos asuntos que incluyen procesos que la encubren, entre ellos, la inauguración o instalación democrática y los procesos de consolidación del régimen democrático, acontecimientos que van más allá de las perspectivas analizadas; lo mismo ocurre en otros contextos en los cuales sólo se tiene en cuenta la transición sin trascender a la consolidación.

A todo este conjunto de procesos -transición, consolidación, democratización- lo denomina Garretón (1990), democratización política, haciendo claridad que el concepto de transición es el paso de un régimen básicamente autoritario a otro, que en la práctica es democrático y que terminado una vez aquél, éste se inaugura en su total dimensión. Y, que una vez culminado, asume su total dimensión, esto es, la democracia 
Al observar la situación y contexto político de América Latina, y relacionándolo con las teorías propuestas, podría decir que las transiciones han terminado en gran parte del continente, aunque se está frente a procesos de completarla, por un lado, y de instalarla y consolidarla, por el otro. Lo que significa que aún puede ser bastante extenso el programa de consolidación en muchos de los países donde las democracias han tenido una esperanza de vida corta o traumática o ha sido de experiencias poco óptimas, hasta tal punto que ya poco se insinúa si en verdad han vivido un proceso de democratización política o ha sido una dictadura camuflada en democracia. Sin ir muy lejos, países como Venezuela, Perú, Ecuador, Guatemala, en parte Colombia y así, podríamos continuar enumerando países que tienen más o menos las mismas similitudes.

En el paso o transición democrática"desde regímenes militares o dictatoriales, se presentan procesos que sólo restituyen un tipo de régimen y, a diferencia de los procesos revolucionarios y de desarrollo, no resuelven otros problemas de la sociedad que los propios de un régimen político" (Garretón, 1990, p. 5); por lo tanto, resolver los demás problemas, bien sean de carácter social, de identidad cultural, de bienestar general, entre otros, es tarea de la consolidación democrática, que expone como mejor argumento la democratización social representada por actores sociopolíticos que logran consolidar, a su vez, una gran mayoría histórica de largo alcance en la vida del nuevo régimen.

Continuando con el análisis propuesto por Garretón (1990), se distinguen al menos tres significados de la idea de transición, en el que cada uno tiene que ver con igual número de modelos o conceptos de democracia que se desarrollan en los regímenes militares, especialmente.

El primer modelo es el que Garretón denomina nueva democracia. En ésta se excluyen las alternativas de cambio real así como los sectores que la representan y, a la vez, se constituye una arena política restringida, aún cuando se reconoce la soberanía popular expresada en el voto universal. Claro está que se mantiene una especie de válvula de seguridad: el poder del veto militar. Para el segundo modelo, este mismo autor considera o, mejor, tiene como preámbulo, el concepto de democracia burguesa o liberal, la cual se define como un conjunto de instituciones jurídicas y políticas propias del 
sistema liberal representativo, donde en verdad se consagran las libertades individuales de todo tipo, se mantiene el respeto por los derechos humanos básicos, se insinúa la competencia y el pluralismo político, se ponen en práctica las distintas formas electorales populares y se reconoce la división de poderes. Esta no es más que una forma de democracia que permite en su interior la competencia por proyectos alternativos. El caso del tercer modelo es el siguiente: se trata nada más y nada menos que el de la democracia real o sustantiva, por contraste con la democracia burguesa, considerada como formal e insustantiva por los sectores de izquierda. Ahora, en esta etapa de transición, se propone una democracia que cumpla con los requisitos de la democracia liberal, pero que además amplíe el campo del cuerpo social, en especial para los sectores populares, como sujeto político y en donde tanto la democracia política como la transformación social aparezcan ligadas de manera indisoluble.

Aplicados los tres modelos a los sectores dominantes, representantes, convencidos de la nueva democracia, la transición no es más que la institucionalización del autoritarismo excluyente, como ideal máximo; como proyecto mínimo, son defensores a ultranza de las conquistas del capitalismo o del neoliberalismo bajo el régimen que representa, básicamente en los momentos de crisis o descomposición del gobierno autoritario.

En cambio, para los que admiten en sus postulados una concepción más clásica de la democracia liberal, la transición significa fin del régimen militar o autoritario, y la posterior consolidación de las instituciones jurídicas y políticas de la democracia representativa. Caso muy similar a la perspectiva que tiene la izquierda frente a este hecho, con la diferencia que se debe incluir la presencia activa de las demandas de la clase popular, consolidándose así, una democracia más participativa.

Todo lo anterior conduce a entender sin ambages la transición como el paso de un régimen militar a una instalación o consolidación democrática, lo que permite la plena realización y reconocimiento del individuo con todos sus derechos y la constitución de espacios de debate en el ámbito sociopolítico. Analicemos un poco el sustento teórico aplicado a la situación de Chile: en este régimen político la transición adquiere diversos significados; 
todo depende del sector político en estudio y la idea de que éste tenga de democracia. Así se puede encontrar un sector de la población que se identifica plenamente con el régimen autoritario y consideran, por demás, que su proyecto fundacional ya llegó al culmen, completó su ciclo al instaurarse la democracia bajo la aplicación de la Constitución de 1980. Lo que se trata de dar a conocer es que en este sector poblacional no habría reformas pendientes, ni trámites políticos que lleven a insinuar cambios en el manejo del Estado, pues ya las negociaciones llegaron a su límite con las reformas a la Constitución, en 1989.

No cabe duda de que la "transición" ha sido deseada y buscada en Chile. Pero desde que el término se inoculó y se instaló a finales de la dictadura de Pinochet, tuvo traducciones "políticas" por completo separadas de la muy deseada transformación económica a que aspiraban las masas que buscaban el fin de la dictadura y de sus dispensas al gran capital. Muy al contrario, la transición tuvo desde entonces también una versión en el surgimiento del socialismo "renovado", que repetía los decires neoliberales mientras proporcionaba su esforzado apoyo a una economía netamente neoliberal, que se levantaba sobre las fundaciones puestas por la dictadura. Y eso siguió por los años y los años, mientras la "política" se balanceaba entre "lo que no se podía hacer" y una alargada vociferación en torno a las expectativas constitucionales, el deplorable expediente sobre derechos humanos siempre pendiente y las aventuras del vitalicio general. En esos años, las privatizaciones seguían su curso inexorable, mientras los informes oficiales se ufanaban de "la transnacionalización del capital chileno". Fríamente podríamos preguntarnos: ¿qué sentido tiene la transición? ¿Para qué la transición?

En cambio, para el sector político compuesto por la oposición, partidarios del socialismo impugnado, considerado sector moderado, haciendo uso de las palabras de Przeworski, la transición nunca llegó a su fin y sería completada una vez se deroguen todas aquellas normas jurídicas y políticas que son un obstáculo para la democracia participativa, aspecto que no fue concertado durante las reformas y las negociaciones de 1989. Fácilmente se harían la pregunta: ¿dónde está la transición? ¿Cuándo ocurrirá una verdadera transición? 
Ahora bien, habrá otro sector de la población que considera que nunca hubo transición y que las reformas o concertaciones democráticas no se pueden aceptar como una reforma constitucional participativa; por lo tanto, lo que se requiere para una verdadera transición no es más que una transformación social definitiva, donde se dé un reconocimiento a las clases populares en todos los espacios políticos y económicos. Este grupo no es más que el sector radical, opuesto al gobierno autoritario o al que lo reemplazó en las reformas políticas.

El anterior análisis basado en el ejemplo de Chile muestra cómo la transición, más que un paso de un régimen a otro, adquiere ciertas aristas que necesariamente se deben tener en cuenta en el proceso de consolidación democrática.

Ahora, retomemos un poco los planteamientos de Adam Przeworski ${ }^{5}$. El argumento de este autor es que la transición política no es más que el período entre un momento en que un régimen autoritario se desmorona o cae y la instauración de la democracia pasa a formar parte de las decisiones políticas. Según los objetivos, recursos, fuerzas concretas y estructura de los conflictos con que se enfrenta la nueva democracia, se pueden distinguir cinco resultados posibles:

a. La estructura del conflicto impide que cualquiera institución democrática perdure: las fuerzas políticas terminan luchando por una nueva dictadura.

b. La estructura del conflicto impide que cualquiera institución democrática perdure: se adopta la democracia como una decisión transitoria.

c. La estructura del conflicto permite la instauración de algunas instituciones democráticas y que sean duraderas en caso de adoptarse: las fuerzas políticas en conflicto luchan por establecer una dictadura.

5 Los postulados del autor son tomados de una entrevista que ofreció a César Cansino, en 1998. La entrevista es subtitulada "Ciencia política y democracia", y fue publicada en el texto: "La ciencia política de fin de siglo", editado por Huerga Fierro, Madrid, 1999. 
d. La estructura del conflicto permite la instauración de algunas instituciones democráticas y que sean duraderas en caso de adoptarse: las fuerzas políticas acuerdan establecer una dictadura.

e. La estructura de los conflictos permite la instauración de las instituciones democráticas que se adoptan.

Las reflexiones y proposiciones dadas por los autores que más han escrutado el campo de las transiciones están centradas en el análisis y en las investigaciones emprendidas en el ámbito de los países latinoamericanos y europeos, tanto de Occidente como de la Europa Oriental, igualmente en estudios llevados a cabo en la región oriental de Asia y el centro de África.

Pero la aplicación de la propuesta de Przeworski y de otros teóricos, caso Garretón, no es tan sencilla. Consideraré de nuevo el caso de Chile, país en el que, como lo anoté anteriormente, la democracia se instauró en el poder mediante una transición negociada entre la dictadura (o régimen dominante) con los sectores no maximalistas o moderados a través de un plebiscito, aunque en éste se aplicaron normas constitucionales propias del autoritarismo.

Los argumentos teóricos de Przeworski muestran que lo sucedido en Chile no fue propiamente una transición sino una "emancipación gradual" de un régimen institucional a otro, con secuelas del primero, esto es, de la dictadura que imperó en el régimen anterior. Si aplicara la fórmula de Przeworski según los cinco aspectos dados a conocer arriba, el caso chileno se podría ubicar entre las etapas D o E. La primera etapa, porque la apertura hacia una transición democrática ocurre en medio de un conflicto que aún no está resuelto, pero se acuerda un marco institucional que permite cierta durabilidad. $Y$ en cuanto a la segunda etapa, el conflicto se puede superar si la institución democrática adopta políticas de consenso, participación y consolidación de la democracia como tal. Posteriormente trataré de analizar esta propuesta para el conflicto en Colombia.

La propuesta de O'Donnell, en cambio, está centrada "en el proceso que lleva de un régimen autoritario a la instauración del sistema democrático representativo" (O'Donnell et al., 1998, p. 30), pero con dos condiciones 
fundamentales: la transición debe ocurrir mediante elecciones libres y éstas deben llevar a la instauración de un gobierno legítimo. La transición tiene como característica fundamental el cambio de una forma de gobierno no democrático, lo que significa un remover las instituciones, costumbres políticas, espacios culturales, para instalar otras nuevas sin perder las identidades propias de la nación.

\section{Liberalización y democratización: bases de la transición}

La liberalización, según los postulados de O’Donnell y Schmitter, no es más que "el proceso que vuelve efectivos ciertos derechos que protegen a los individuos y grupos sociales ante actos arbitrarios de violación cometidos por el Estado o por terceros" (O'Donnell et al., 1998, p. 30). Los protegidos por el Estado pueden reconocerse, o bien en la constitución política, o bien en el Derecho Internacional Humanitario. En cambio, cuando los actos de violación los comenten grupos de extrema izquierda o derecha se acude por lo general a la protección del Derecho Internacional.

Los elementos de liberalización incluye aspectos como el "habeas corpus", derecho a la defensa según el debido proceso y de acuerdo con las leyes, el "habeas data", la libre movilización, la inviolabilidad de la correspondencia y la vida privada.

Cuando existen organizaciones o grupos formalizados acuden por lo general a la liberalización para manifestar su discrepancia o desacuerdo con la política oficial, sin que el Estado entre a reprimir las manifestaciones de rechazo u oposición. Casi que podría afirmar que los espacios en torno a la unión o a la congregación que convoquen a la acción liberalizadora son espontáneos, porque obedecen básicamente al logro paulatino de ciertos derechos individuales y al reconocimiento que éstas hacen de las leyes hacia garantías colectivas. Esta se reconoce como una primera etapa de la transición y obedece a la forma casi insulsa, precaria y ambigua como el régimen autoritario ejerce el poder. 
Pzeworski considera que los grupos, las organizaciones colectivas y las manifestaciones de rechazo hacia el régimen tienen como base en la dictadura permitir que estas fuerzas se organicen y se constituyan en parte contra-hegemónica del "status quo". En realidad, la solución no está en el desmoronamiento de su legitimidad, sino en permitir proyectos colectivos para un futuro alternativo, pero cuando al interior del gobierno autoritario se presentan fisuras y roces, la sociedad civil las aprovecha e inicia su organización autónoma, sin recibir represión alguna, lo que marca el inicio de la liberalización y la futura transición.

Casi podría argumentar que sin una activa liberalización, la transición se hace más difícil, más complicada, y los espacios de representación política en la transición y consolidación del nuevo orden institucional reflejan hasta qué punto los logros y aciertos fueron los más adecuados y pertinentes o no. Todo esto obedece a que en el proceso de liberalización se presenta generalmente un choque entre los grupos inmovilizadores y los liberadores. Una serie de contradicciones van ampliando la brecha que ha cedido el régimen o las llamadas fisuras políticas, hasta llegar a la instauración de otro régimen.

Por tanto, la liberalización es el resultado de una interacción entre la aparición de fisuras en el régimen autoritario y la organización autónoma de la sociedad civil. Cuando los grupos liberadores llegan a ciertos acuerdos o consensos, aprovechan mejor las fisuras del régimen y se abren nuevos espacios políticos de concertación para la organización autónoma. Las transformaciones, el nivel de organización, la movilización y la integración, marcan el ritmo de la transición que a veces puede durar varios años o viceversa: el proceso será de unos cuantos años.

Una vez más tomaré el caso chileno y trataré de aplicar las hipótesis propuestas por Przeworski y demás autores. En Chile... ¿Cuándo comienza el proceso de liberalización? Aplicando la tesis de Przeworski, ésta se inicia con la interacción entre la aparición de fisuras en los que apoyan al régimen y la organización autónoma de la sociedad civil. Es posible que las propuestas presentadas en 1983, diez años después de impuesto el régimen dictatorial, hayan cristalizado la alianza contra el gobierno. Así continuaron las movilizaciones populares, se aprovecharon las fisuras hasta que el régimen dio 
los primeros pasos encauzados hacia una negociación política: se nombra un nuevo ministro de interior y los liberadores ganan terreno; aunque poco después el dictador volvió a la intransigencia. En el paso previo a la negociación se habrá de tener en cuenta los actores políticos que tomaron parte en el movimiento. Para este análisis, los hubo de parte del régimen, de la oposición, como también de la oposición dura, los blandos, los radicales y hasta los conciliadores. En síntesis, lo que se logró con las fuerzas de transición fue la liberalización y posterior democratización del régimen, lo que hizo posible el plebiscito y luego las elecciones libres. Los analistas Ilaman a este fenómeno autoritarismo liberalizado o dictablanda. El término obedece a que la liberalización no puede exceder ciertos límites sobre los cuales el nuevo gobierno o el gobierno moderado mantiene restricciones, coarta ciertas libertades, aplica normas de control a los grupos "inmaduros" para el ejercicio político y establece así una democracia limitada o inmadura.

\section{El camino a la socialización y consolidación}

La cuestión más compleja de la transición política no es propiamente el proceso como tal, esto es, llegar a la posible implantación de la democracia como una de las metas finales, sino el qué hacer con la democracia una vez instaurada. Przeworski (1998, P. 161) afirma que la democracia no es más que ese proceso de institucionalización de la incertidumbre, de la inestabilidad misma a la que se someten tanto los intereses individuales como colectivos. Al llegar a esta etapa, consideran O’Donnell y Schmitter, es inevitable una segunda transición donde se dé un tratamiento equitativo a todos los ciudadanos, se hagan convenios y consensos y se ponga en práctica una igualdad sustantiva en cuanto a beneficios. Esta fase adquiere el calificativo de socialización o segunda transición (O'Donnell et al., 1998).

Para una adecuada segunda transición, se deben involucrar todos los actores sociales, hacer un reconocimiento de sus derechos, dotar a cada individuo de formas de participación política y establecer una democracia en el sentido pleno que se caracterice por la calidad de vida, ingresos monetarios de acuerdo con la capacitación, la plenitud en derechos fundamentales: salud, educación, vivienda y tiempo para la autorrealización personal. 
Una vez se llega al plano de la socialización, inicia el proceso de consolidación, término que bien emplea Morlino (1986) para hacer referencia a los países que lograron la instauración democrática en Europa después de varias guerras civiles, conflictos internos y crisis económico-políticas. Estos países fueron Portugal, España, Grecia, entre otros. La revisión histórica y los análisis que hace Morlino, lo llevan a una aproximación a lo que puede considerarse como consolidación democrática: apunta a que "es un método o conjunto de reglas de juego que sirven para permitir la participación y competición de todos los ciudadanos" (p. 26).

Las reglas se substancian en estructuras, procedimientos, normas, guías para la solución de conflictos de forma pacífica. Una vez solucionado el conflicto adquieren fuerza los derechos políticos, las organizaciones libres, la igualdad política, los derechos fundamentales, entre otros aspectos de la vida social y política. Es más, la regla sólo es posible en el tránsito dado desde un período autoritario, bien sea de largo alcance o, en caso extremo, pasajero. Por lo tanto, la consolidación democrática es un hecho a priori, causado por actores significativos y relevantes del conflicto.

Estas reglas (o núcleo procedimental del juego democrático) regulan el acceso por la vía de la competencia al gobierno, acceso que se garantiza a través de la protección de los derechos de la oposición y sus perspectivas de ganar y los derechos de los que gobiernan.

En consecuencia, es importante que las reglas se fijen al gusto de todos, tanto de los que gobiernan como de los que son gobernados, situación que hace de lo primordial, no el ganar o perder, sino mantenerse en juego. La esencia de la consolidación está en definir y fijar reglas para la competición. Ahora bien, no existe ningún medio universal válido para intentar la consolidación, porque no hay un grado o máximum óptimo de reglas que detenga a todos los participantes en el mayor número de circunstancias.

La democracia, en este caso, funciona en palabras de Rustow, (1970, pp. 337363) como una especie de juego abierto sin resultados predeterminados, lo que significa que las reglas de este juego tienen un parámetro instrumental más que un consenso popular o elitista preexistente sobre los fundamentos. 
Todo es cuestión de habilidad para atraer a los jugadores hacia el juego y hacer que participen de él.

En este instante, es posible hacer un segundo acercamiento al concepto de democracia, dadas las consideraciones anteriores. Ésta no es más, según Morlino (1989), que:

un conjunto de estructuras y procedimientos, explícitos y determinados $a$ priori sobre la resolución de los conflictos recurrentes y continuos. Esos ordenamientos políticos son el resultado, incluso temporal y hasta casual, de un acuerdo-compromiso pos-autoritario, con resultados sustantivos relativamente inciertos (p.12).

El acuerdo o compromiso lo establecen las estructuras de mediación, ligadas a los distintos intereses presentes y protagonistas de las diferentes instancias de decisión. Y, en este acuerdo, consenso o diálogo entre iguales, la consolidación juega un papel vital en el proceso de reforzamiento, robustecimiento del sistema democrático, encaminado al aumento de la estabilidad y a la prevención de las posibles crisis.

O’Donnell dice al respecto que la consolidación es lo mismo que la consecución de la legitimidad por parte de un régimen. Claro está que para tal fin deben existir unos criterios procedimentales; uno de los ejemplos en este caso consistió en el acuerdo entre los partidos Liberal y Conservador de Colombia, para rotarse el poder durante 16 años, cada cuatro años. Este fenómeno es conocido como el Frente Nacional (O'Donnell et al., 1998).

La situación puede ser problemática en la medida en que se produzca una repetición y acumulación de sucesos o la falta de madurez del gobierno, o simplemente, no ayude a la consolidación, que no de participación (significa que no da opción a los que quieren participar del juego de la democracia) a los jugadores, a los opositores y gestores de los momentos tanto de liberalización como el de la socialización.

De manera más sencilla, la consolidación democrática, parafraseando a Schmitter (1984), consiste en un proceso que supone la estructuración de diversos regímenes parciales cada uno ligado a instituciones diferentes, con sus respectivos clientes o público votante. 
Los "momentos fluidos y confusos en que están a punto de surgir nuevas estructuras democráticas, pero al mismo tiempo permanecen algunas estructuras propias del antiguo régimen" (Morlino, 1986, p. 136), o lo que es lo mismo, la transición, en palabras de Morlino, permiten el salto cualitativo y cuantitativo, en el momento de paso de un régimen a otro. Pero este no es el límite, porque las expresiones democráticas no se agotan en la sola transición, sino que deben continuar hacia otra fase o etapa: la instauración o "diseño de nuevas instituciones y procedimientos propios de un sistema democrático, que varía de acuerdo con el grado de rapidez y tiene un proceso de adaptación en las diferentes estructuras y normas democráticas" (Morlino, 1986, p. 135). La ampliación de la legitimidad democrática lo hace de forma más ecuánime.

Las ideas centrales de este acápite están sustentadas en lo siguiente: la consolidación es diferente a la estructuración, es decir, sólo puede haber consolidación cuando ya ha habido una estructuración. La consolidación también es diferente al encapsulamiento (el proceso para limitar y constreñir los conflictos), lo que significa que, durante la consolidación, las reglas básicas del ordenamiento se hacen valer, son aceptadas y los conflictos no se eliminan del todo; por último, la consolidación es diferente a la institucionalización, en cuanto que esta última obedece al reconocimiento del nuevo sistema político.

La consolidación, para este análisis, se debe entender como el momento en que culmina la transición, esto es, cuando ya no se cuestiona en absoluto la competición. La relación causal entre consolidación e institucionalización es lo que las hace interesantes.

De acuerdo con lo anterior, se llega a otra reflexión más amplia sobre consolidación democrática. Dice Morlino (1986) que consiste en el "proceso de adaptación, congelación de estructuras y normas democráticas que son aceptadas como legítimas en parte, o del todo, por la sociedad civil" ( $p$. 135). Para que sea efectiva, debe ocurrir la exclusión del campo coercitivo o poder militar. 
En este campo se establece la diferencia con la consolidación en el sistema político, que se relaciona más con el esfuerzo organizativo, la adquisición y fortalecimiento de la identidad, la formación de alianzas parlamentarias de apoyo al gobierno, la creación de partidos.

Según O’Donnell et al. (1998), convocar a elecciones significa que los partidos políticos deben emerger para convertirse en los actores principales de la política, conseguir apoyo en el ámbito nacional y definir e implantar las reglas de la contestación. De no existir un entendimiento previo, las elecciones y los parlamentos perderán eficacia, caso típico de las elecciones en la gran mayoría de los países latinoamericanos.

Cuando existe un grado de legitimación-integración alcanzado por el ordenamiento democrático, las amenazas políticas pierden fuerza, al igual que los grupos de oposición del juego democrático, y si no se llega a la etapa de la consolidación, la democracia entraría en crisis, inestabilidad, debilidad del Estado, y el papel de los partidos no tendría sustento democrático.

Aún así, las estructuras y los procedimientos democráticos, las relaciones entre las estructuras o los poderes, los partidos y sistemas políticos, las relaciones de mediación-sociedad civil y las de estructuras mediación-régimen se pueden ver afectadas de acuerdo con el ámbito que tiene la consolidación.

La propuesta de Morlino (1986) culmina dando una serie de rasgos que considera vitales de acuerdo con el rumbo que puede tomar la consolidación, tales como el mantenimiento y puesta en marcha del compromiso democrático, el respeto a la legalidad, la neutralidad y neutralización de los militares, la garantía de los intereses a los grupos empresariales, las estructuras institucionales y su papel en el sector público, en la economía, entre otros. Rasgos con los que prácticamente sustenta su teoría.

Por lo tanto, considero como hipótesis finales sobre la consolidación las siguientes:

- Cuanto más amplio, rápido y complejo es el espectro de partidos que surgen y se organizan durante la transición y la instauración, integrándose en el nuevo régimen, tanto más probable es la consolidación. 
- Si los protagonistas de la instauración son fuerzas democráticas moderadas de derecha o de centro-izquierda es más probable la consolidación.

- Una cultura política poco radicalizada, así como la memoria histórica dejada por los costes sufridos durante el período autoritario, o bien el resultado de las profundas transformaciones socio-económicas ocurridas durante ese período, pueden generar ventajas para la consolidación.

- La pertenencia del país a un área geopolítica, ya completamente democratizada, y el ingreso en organizaciones económicas supranacionales influyen sobre las fuerzas políticas del país y la posterior consolidación.

\section{Escenarios de transición en Colombia: Constitución de 1991}

El escenario planteado por O’Donnell et al. (1998), en cuanto que la transición consiste en el paso de regímenes autoritarios hacia "un destino incierto", pero en todo caso distinto, y el planteado por Morlino (1986), en cuanto que la considera como aquellos"momentos fluidos y confusos en que están a punto de surgir nuevas estructuras democráticas, pero al mismo tiempo permanecen algunas estructuras propias del antiguo régimen" (p. 136), conducen a una comprensión de que, posiblemente, la llamada transición no sea más que una rotación en el poder de gobiernos sucesivos que fracasan en el establecimiento de soluciones permanentes para lograr una cierta institucionalidad política o, finalmente, la generalización de la confrontación violenta.

Ahora bien, una de las características de los procesos de transición es la indefinición de las reglas de juego, no sólo por el flujo constante de dichas reglas, sino por el propio conflicto que se teje en torno a su determinación. Los actores luchan no sólo por la satisfacción de sus intereses inmediatos, sino también por la definición de las reglas y de procedimientos cuya configuración determinará los ganadores y perdedores del futuro. O'Donnell et al. (1998) afirman: "De hecho, estas nuevas reglas definirán claramente cuáles son los recursos que pueden ser utilizados legítimamente en la arena política, así como a los actores a los que les será permitido participar" (p. 3). En este juego complejo, los procesos de transición pueden tomar diversas 
rutas y generan múltiples formas de democracia con distintas posibilidades de consolidarse.

Al retomar el caso de Colombia y haciendo un esfuerzo teórico y crítico a las observaciones de los transitólogos, las transformaciones que vivió el país en los años de 1989 a 1991, en particular las impulsadas por la Asamblea Nacional Constituyente, no provinieron de una presión de masas dada la extrema debilidad de los segmentos opositores y la fragmentación de los sectores populares. Además, el poco reconocimiento que posee la sociedad civil en nuestro medio y la limitación para los espacios de concertación dan a entender que a este intento le faltaba una suficiente presión política que permitiera quebrar las resistencias inmovilistas al cambio, provenientes de los sectores partidarios del "status quo" incrustados en la Corte Suprema de Justicia, en el parlamento y en los partidos. Por ello, en el contexto del proceso de paz y de la emergencia de fuerzas políticas distintas a las del bipartidismo, se impondría una reforma pactada.

Así que la Asamblea Nacional Constituyente no inició en Colombia un proceso de transición democrática, si se entiende por este concepto el paso de un régimen autoritario a un régimen democrático de acuerdo con las propuestas teóricas expuestas. Lo que se ha buscado impulsar es un proceso de apertura o profundización democrática, similar al que hubo en México. Es decir, más que un cambio de régimen, en Colombia se comenzó a gestar un cambio en el régimen, claro está, de una profundidad histórica, sin antecedentes en el país.

En síntesis, para el caso colombiano, estas cuestiones de la transición se expresan en cuatro desafíos: 1) cómo evitar una contrarreforma constitucional o una labor obstruccionista en el Congreso, que impida desarrollar las nuevas normas constitucionales y que pueda significar un retorno triunfal de las viejas prácticas políticas; 2 ) cómo impedir un agravamiento del orden público ante el fracaso de la política de paz o ante una reactivación del narcoterrorismo; 3) cómo introducir las necesarias reformas económicas que requiere el país sin caer en el neoliberalismo extremo, con sus enormes costos y tensiones sociales; y, finalmente, 4) cómo llevar a cabo una reducción de las prerrogativas militares y alcanzar un control civil del orden público, sin generar graves tensiones civiles y militares. 
En los años 1989, 1990 y 1991, según el analista Díaz-Callejas $(1992)^{6}$, se conforma uno de los períodos más contradictorios, dinámicos y creadores en la historia de Colombia, país que por tradición ha sido de sociedades conservadoras, violentas, con un sinnúmero de confrontaciones políticas y donde, en pleno siglo XX, excluidas las guerras de independencia frente a España, hubo 8 guerras civiles generales, 14 locales, 3 golpes de cuartel y centenares de choques sangrientos menores en ciudades, municipios, pequeños poblados, todos entre liberales y conservadores y que, desde 1947, con diversas motivaciones, sectores y métodos, incluido el narcotráfico, ininterrumpidamente, hasta nuestros días, soporta una violencia política y acciones terroristas que han causado una cantidad de muertes incalculables.

La situación de caos e incertidumbre fue la que abrió las compuertas para que el entonces presidente César Gaviria Trujillo convocara a una Reforma Constituyente para dar paso a una nueva Constitución Política según las necesidades del presente siglo. Todo obedece a que, por más de cien años, Colombia vivió bajo el imperio de la Constitución de 1886, que había institucionalizado una democracia centralista, autoritaria, restrictiva y restringida con el sello del Estado de sitio. Esta figura permitió, entre 1886 y 1991, poner al país bajo el régimen de excepción en diferentes períodos, por más de 50 años. Las reformas suscitadas en la Constitución, la cual abrió la brecha para que tanto opositores como partidarios del gobierno calificaran este trance como un período transicional, toda vez que la Constitución de $1991^{7}$ rompió con la tradición elitista colombiana, estaban basadas en la participación popular: el pueblo nombró a sus miembros en elecciones directas; los indígenas y las comunidades negras participaron igualmente con sus propios voceros; también lo hicieron ex juristas, médicos, ex guerrilleros, líderes sindicales, literatos, predicadores, protestantes, entre otros.

6 En el texto, Apolinar Díaz-Callejas retoma los conceptos del ex presidente Alfonso López Michelsen, así como los de H. C. F. Mancillas, un analista boliviano, y un estudio hecho por Richard Morse (1982): El espejo de Próspero: un estudio de la dialéctica del nuevo mundo, editado en México por Siglo XXI. DíazCallejas desarrolla una transición del paraestado colombiano a través de diferentes épocas y analiza las propuestas políticas.

7 La Constitución de 1991 obedece a una reforma constitucional convocada por el entonces presidente del país, César Gaviria Trujillo. En ésta participaron 70 constituyentes, más dos indígenas con derechos propios y dos ex guerrilleros. Se reformó la antigua Constitución de 1886 y se dio vía libre a "un nuevo país", según la expresión del mandatario. 
(el sentido está bien. El argumento consiste en que se abrió la brecha para que particiaparan diversos actores en la confrontación democrática)

La Constitución del 91 eliminó lo artificioso y falso, se descomplicó y trabajó con la informalidad del caso, se acordaron además los diálogos del gobierno con las guerrillas del M19, del Ejército Popular de Liberación (EPL), del Partido Revolucionario de los Trabajadores (PRT) y el Quintín Lame; los otros dos grupos, Fuerzas Armadas Revolucionarias de Colombia (FARC) y el Ejército de Liberación Nacional (ELN) se mantuvieron a la expectativa del proceso, sin tomar partido.

La composición de la constituyente, por sí sola, es indicativa de los cambios políticos que estaban en marcha. La novedad consistió en que, por primera vez en la historia de Colombia, los partidos tradicionales no tuvieron mayoría en el campo legislativo.

La transición para los que refuerzan esta idea fue una dura marcha y un reconocimiento a los nuevos movimientos políticos, sociales, cristianos, indígenas y ex guerrilleros, la cual se enmarca en la Constitución de 1991 y define a Colombia como un Estado Social de Derecho, organizado en forma de República unitaria, descentralizada, con autonomía de sus entidades territoriales, democrática, participativa y pluralista, fundada en el respeto a la dignidad humana, en el trabajo y en la solidaridad de las personas que la integran y en la prevalecía del interés general. Se reconoce y protege la diversidad étnica y cultural de la nación; consagra que las lenguas y dialectos de los grupos étnicos también son oficiales en su territorio y hace obligatoria la enseñanza bilingüe; otorga a las comunidades indígenas dos senadores que eligen directamente por circunscripción nacional especial; dispone que las relaciones exteriores se fundamenten en la soberanía nacional, la autodeterminación de los pueblos y los principios del derecho internacional; así mismo, autoriza la doble nacionalidad; da cargo constitucional al derecho de paz; eleva a categoría constitucional el derecho a la vida, a no ser sometido a desaparición forzada, tortura, tratos o penas crueles e inhumanos, a la personalidad jurídica, intimidad personal y familiar y a su buen nombre, a todas las libertades, individuales y sociales, al "habeas corpus", a la libre asociación y a la formación de sindicatos e igualmente prohíbe la extradición de colombianos. 
Además, consagra los derechos sociales, económicos y culturales, así como la seguridad social, la salud, la educación, la recreación, la vivienda digna, el bienestar de familia y del medio ambiente; instituye mecanismos de participación popular democrática como el voto, el plebiscito, el referendo, la consulta popular, el cabildo abierto, la iniciativa legislativa y la revocatoria del mandato y la acción de tutela, para reclamar ante los jueces en todo momento y en todo lugar; elimina la figura del Estado de sitio, sustituyéndola por la conmoción interior y exterior; reorganiza la administración de justicia, creando los jueces de paz, e institucionaliza la autonomía de las entidades territoriales.

Ahora sí, trataré de dejar algo claro: la transición, en palabras de Schmitter (1984), adquiere reconocimiento en la medida en que "existen reglas y procedimientos efectivos, que suelen estar en manos de gobernantes autoritarios" (p. 38). Más allá de los anteriores espacios, está la liberalización, que según el mismo autor, amplía los derechos, hasta llegar a la democratización o el derecho de ser tratado como humano.

Según nuestra experiencia como nacionales, en Colombia no hubo una transición de un régimen a otro mediante la reforma a la Constitución; no se pasó a algo diferente en la práctica, porque aún persiste la violación de los derechos fundamentales, el desarraigo, la exclusividad política, la concentración de bienes materiales en unas pocas manos y la discriminación en derechos de salud, educación y vivienda. Tal vez Colombia ha entrado en un período de transición hacia un nuevo tipo de democracia: de la representativa pasó a la participativa, pero no será una marcha en línea recta, porque más de 150 años de dominación de una cultura y lealtades políticas fundadas en el exclusivismo bipartidista (liberal/conservador) no se cambian de la noche a la mañana.

Una última acotación me permite señalar que, para evaluar las estrategias que se están utilizando para consolidar el cambio político en curso, es indispensable determinar previamente los factores que produjeron el propio clima de cambio, es decir, las dimensiones de la crisis. Santamaría (1981) sostiene, tras considerar las experiencias de transición ocurridas en Europa en los años setenta, que "el cambio de régimen es siempre la respuesta a una alteración 
sustantiva en el interior o en el entorno del régimen preexistente a la que éste es incapaz de adaptarse" ( $p, 7)$. Santamaría formula esta apreciación general después de realizar una aguda crítica a Dankwart Rustow, dado que su modelo no es susceptible de aplicación universal. A pesar de esta limitación, es de enorme interés para el caso colombiano retomar un poco los análisis de Rustow que se acomodan bien a nuestra experiencia reciente. En efecto, para este autor, el cambio político tiene lugar en el momento en que un prolongado conflicto no tiene ya solución por la fuerza. La tolerancia resulta más fructífera que la represión debido a la amenaza de un desbordamiento de los conflictos. Se impone, pues, la negociación y la integración de los actores excluidos en el juego político. El nuevo clima se consolida una vez se haya comprobado la eficacia de las normas constitucionales para canalizar los conflictos políticos y sociales.

La experiencia muestra que la alteración sustantiva ocurrida en Colombia se enmarca en el colapso parcial del precario Estado a consecuencia del doble frente de batalla que debió afrontar la administración de Virgilio Barco: el ascenso de la insurgencia armada gracias a la conformación de la Coordinadora Guerrillera Simón Bolívar (CGSB) y la escalada de acciones urbanas desestabilizadoras, además del narcoterrorismo. Esta aguda crisis está acompañaba de un empate negativo entre las fuerzas armadas y los grupos insurgentes, situación que empujó a los sectores dominantes de la elite a acelerar el proceso de paz, a negociar acuerdos políticos impensables en otras circunstancias, e incluso, a integrar en el propio gabinete al jefe del partido incorporado al sistema político M19.

Como consecuencia del pacto político, según lo expone Rustow, (1970, p, 38) se dio el origen al actual proceso de democratización, cuyos rasgos se aproximan más al modelo de cambio político ligado a la resolución de una conflagración armada (como en el Salvador), que al modelo de sustitución de un régimen autoritario como ocurriera en las naciones mediterráneas de Europa o en el Cono Sur del continente americano.

Los postulados anteriores no impiden poner sobre el tapete las consideraciones de otros analistas que argumentan que al ser Colombia el país con la democracia más antigua de América Latina, sin caudillos despóticos, ni 
dictadores de larga duración, basados en investigaciones según las cuales en el territorio no ha habido tiranías parecidas en lo más mínimo a las de Juan Vicente Gómez Duvaller, en Haití; Somoza, en Nicaragua; Trujillo, en el Salvador; Batista, en Cuba; Pinochet, en Chile; Videla, en Argentina; Stroessner, en Paraguay. Sin desconocer que no hayan habido espacios antidemocráticos y represivos, amparados en el Estado de sitio o en el Estatuto de Seguridad, como el creado por Turbay Ayala, en 1979, aún así, lo muestran como un país sólido, pero con una "democracia blanda"8, de acuerdo con las perspectivas de las teorías políticas de hoy.

En este sentido, cobran vigencia las palabras de Morlino (1986), en cuanto a lo que he señalado respecto a los momentos fluidos y confusos en los cuales están a punto de surgir nuevas estructuras democráticas, pero que al mismo tiempo permanecen otras estructuras del antiguo régimen. Significa que Colombia está lejos de una verdadera transición democrática o, al menos, mientras el Estado no ejerza un absoluto control sobre el territorio y cubra todos los espacios que hoy están en manos de la guerrilla, los paramilitares y el narcotráfico.

Es más, si se tratan de aplicar los postulados de Przeworski (1998, p, 163)al contexto colombiano, parece ser que la situación del país se ubicara mejor en las alternativas A-B-C, en las cuales la estructura del conflicto impide que una institución democrática perdure y sea más factible adoptar la dictadura o una "democradura" o "dictablanda".

\section{Unas últimas ideas}

Una vez aclarados los conceptos básicos sobre la liberalización, la transición, la democratización y la consolidación, queda para la retina del lector una especie de duda cartesiana, cuando empieza a notar diferencias y semejanzas que pueden ser poco significativas, pero de gran alcance a la hora de

8 El término democracia blanda aparece referenciado por Schmitter y desarrollado por O'Donnell, en el mismo artículo (O’Donnell et al., 1998); según el autor, los convierte en "blandos" su creciente conciencia de que el régimen que contribuyeron a implantar y en el cual por lo común ocupan cargos importantes tendrá que recurrir en un futuro previsible a algún grado o forma de legitimación electoral. En este sentido otorga ciertas libertades a los sectores moderados. 
ponerlas en práctica en los sistemas políticos subyacentes. Para tal fin, haré unas cuantas aclaraciones sobre lo ya escrito en el documento elaborado.

Lo primero es que la consolidación no es más que el proceso de reforzamiento, el robustecimiento del sistema democrático, que va precisamente encaminado a aumentar la estabilidad de éste, su capacidad de persistencia, y a contrarrestar o prevenir posibles crisis que lo puedan afectar. El resultado de este proceso no es otro que el reforzamiento-afirmación de los ordenamientos democráticos, como también puede ser el punto de llegada lo que permite identificar a plenitud una institución consolidada. No podría existir una consolidación democrática si previamente no se ha presentado la transición reconocida, en palabras de Morlino (1986), como el momento fluido y confuso en el cual están a punto de surgir nuevas estructuras democráticas, pero permanecen al mismo tiempo estructuras propias del régimen antiguo, sin que la adecuada consolidación esté cimentada sobre la posibilidad o posibilidades de surgir de la transición, de su instauración y permanencia.

Me detengo básicamente en la consolidación para emprender así un mejor análisis de los procesos políticos que la hacen posible:

Al considerar la consolidación como el proceso de fijación de un sistema político esencialmente democrático en sus características fundamentales y como proceso de adaptación en los aspectos secundarios de las diferentes estructuras y normas democráticas influidas por el transcurso del tiempo, factor que puede llevar a crisis, rupturas y cambios, se podría obtener como premisas fundamentales las siguientes: 1) que la congelación-adaptación de un régimen posibilite la consolidación; 2) que ocurra una progresiva ampliación de la legitimidad del régimen; 3 ) que encuentre una serie de diferencias como: a) cuando la consolidación es diferente a la estructuración porque sólo puede haber consolidación cuando ya ha habido una estructuración (esta es la fase primordial); b) cuando la consolidación es diferente al encapsulamiento, lo que significa que durante la consolidación las reglas básicas del ordenamiento democrático se hacen valer; y c) cuando la consolidación es diferente a la institucionalización, porque la institucionalización es la fase previa a la consolidación. 
Vistas las anteriores apreciaciones se podría, ahora sí, congregar los términos para definir con más criterios lo que puede significar una consolidación: es el proceso de adaptación de estructuras y normas democráticas aceptadas como legítimas, en parte o del todo, por la sociedad civil. Este proceso complejo y variado se desarrolla en diferentes direcciones y alcanza tal refuerzo de aquellas instituciones y normas como para posibilitar su persistencia.

En cambio, la no consolidación significa que una determinada democracia, tras la instauración en los años siguientes, desemboca en la vía de crisis o de la inestabilidad. El éxito de la consolidación significa dar comienzo a la fase de persistencia.

¿Cuáles ámbitos pueden afectar la dirección que tome la consolidación?

- Las estructuras y procedimientos democráticos.

- Las relaciones entre las estructuras o poderes previstos en el ordenamiento del país.

- Los partidos y sistemas de partidos.

- Las estructuras de intereses o grupos de presión.

- Las relaciones de estructuras de mediación-sociedad civil.

- Las relaciones de estructuras mediación-régimen.

Si se logran modificar ciertas conductas o pautas que puede llegar a tener la consolidación y establecer unas características afines, se podrían lograr modalidades del proceso de consolidación tales como:

- La aparición de pautas de comportamiento (modelos de comportamiento repetidos en el tiempo).

- La adaptación institucional (adaptación progresiva de las instituciones a la realidad democrática diseñada por la Constitución y el ordenamiento democrático).

- La identidad (adquisición de identidad por parte de las instituciones). 
- La autonomía de las instituciones respecto de la sociedad civil, en la cual se reconocen la aparición de los poderes legislativo, ejecutivo y judicial.

- El esfuerzo organizativo (conseguido por el paso del tiempo y la legitimación del funcionamiento de las instituciones).

Las anteriores modalidades, que podría tomar la consolidación, permiten reconocer algunos de los rasgos comunes propios de las distintas direcciones para que se lleve a cabo. Estos rasgos son, entre otros: a) el mantenimiento y puesta en marcha del compromiso democrático, que es esencial para que se logre la verdadera consolidación; b) el respeto de la legalidad, lo que la hace reconocible por todos; c) la neutralidad o neutralización de los militares, lo cual lleva a que no puedan tomar participación en el sistema político, sin previo consentimiento del gobierno consolidado; d) la instauración de ciertos grupos empresariales privados que ven garantizados plenamente sus intereses; e) acordar el papel que le corresponde a los partidos y al sistema político; y f) fundamentar las estructuras del régimen, como la económica, la política, educativa, del sector público, etc.

Aunque el fin del ensayo consiste en mostrar los aspectos relacionados con las transiciones políticas, una vez revisadas las teorías e investigaciones ofrecidas por los expertos en el tema, ya reseñados en el transcurso del mismo, ahora es más fácil reconocer que no es posible una transición sin una previa liberalización, una adecuada democratización y una posterior consolidación, etapas que por lo complejo de los sistemas políticos se hace extenso, de mucha rigurosidad $y$, a veces, hasta imposible de lograr.

\section{$\mathbf{R}_{\text {eferencias }}$}

Dahl, R. (1992). La democracia y sus críticos. Barcelona, España: Paidós.

Díaz-Callejas, A. (1992). La Sinuosa Marcha de la Transición Colombiana. Revista Nueva Sociedad, 119.

Garretón, M. A. (1990). Del autoritarismo a la democracia política ¿Una transición a reinventar? (Documento de trabajo FLACSO-programa Chile). Estudios políticos No5, Santiago de Chile, Chile.. 
González, C. y Sánchez-Roca, M. (Eds.). (2000). Política y democracia. Lecturas de ciencia política. Madrid, España: UNED.

Morlino, L. (1986). Consolidación democrática, definición, modelos, hipótesis. Revista de la REIS, 135 (26).

O’Donnell, G., Schmitter, P. C. y Whitehead, L. (Eds.). (1998). Transiciones desde gobiernos autoritarios. Buenos Aires, Argentina: Manantial.

Santamaría, J. (Ed.). (1981). Transición a la democracia en el sur de Europa y América latina. Madrid, España: Tecnos.

Schmitter, P. (1984). Patti e Transizioni: Mezzi non-democratici a fini democratici? Rivista Italiana di Scienza Politica, 14 (3), pp. 37-47.

Rustow, D (1970). Transitions to Democracy. Toward a Dynamic Model, Comparative Politics, $\mathrm{n}^{\circ} 12$,

Cansino, C. (1999). Ciencia política de fin de siglo. Madrid: Huerga Fierro.

Przeworsky, A. (1998). Ciencia política y democracia. En: Cansino C (1999). Ciencia política de fin de siglo. Madrid: Huerga Fierro. 